\title{
Risk Analysis of Water Resources Crisis in the Lancang - Mekong River Drainage Basin under the Background of Climate Change
}

\author{
Ren Zhang ${ }^{1,2}$ \\ ${ }^{1}$ College of Meteorology and Oceanography, PLA Univ. of Sci. \& Tech. , Nanjing 211101, China \\ ${ }^{2}$ Nanjing Information Technology University, KLME, Nanjing 210044, China \\ Email: zren63@126.com \\ Hengwan Zou \\ College of Meteorology and Oceanography, PLA Univ. of Sci. \& Tech. , Nanjing 211101, China \\ Mei Hong \\ College of Meteorology and Oceanography, PLA Univ. of Sci. \& Tech. , Nanjing 211101, China \\ Aixia Zhou \\ College of Meteorology and Oceanography, PLA Univ. of Sci. \& Tech. , Nanjing 211101, China \\ Gang Zeng \\ Nanjing Information Technology University, KLME, Nanjing 210044, China \\ Received 24 June 2012 \\ Accepted 1 October 2012
}

\begin{abstract}
Aiming at the deteriorating variation trends and potential crisis of water resources in the Lancang-Mekong River Basin under Climate Change, from the view of risk analysis, a conceptual framework of tropical cyclone disaster risk is established, an assessment index system of water resources crisis risk in Langcang-Mekong River Basin are explored based on the thought of AHP, and using the risk index assessment method, an assessment index system is established. Then, the risk assessment of water resources crisis in the Lancang - Mekong River Basin under Climate Change is carried out.
\end{abstract}

Keywords: Lancang - Mekong River; Water Resources; Risk Assessment.

\section{气候变化背景下澜沧江-湄公河流域水资源危机风险分析 \\ 张韧 ${ }^{1,2}$, 邹恒琬 ${ }^{1}$, 洪梅 ${ }^{1}$, 周爱霞 ${ }^{1}$, 曾刚 ${ }^{2}$ \\ 1解放军理工大学气象海洋学院, 南京 211101 , 中国 \\ 2 南京信息工程大学 KLME, 南京 210044, 中国}

摘要：针对气候变化背景下澜沧江-湄公河流域水资源变化趋势和潜在危机，从风险分析的角度建立了水资 源危机的风险概念框架; 基于层次分析法思想探索了澜沧江-湄公河流域水资源危机风险的体系结构，采用 风险评价指数方法初步构建了水资源危机风险评估模型，进行了气候变化背景下澜沧江-湄公河流域水资源 危机风险的实验评估。

关键词：澜沧江-湄公河, 水资源, 风险评估 


\section{1. 引言}

澜沧江-湄公河发源于我国青海省唐古拉山脉, 在我国境内称为澜沧江, 自云南南腊出境后称为涺 公河, 在越南胡志明市以南流入南海。该河流从北 向南依次流经我国青海、西藏和云南三省以及缅 甸、老挝、泰国、柬埔寨和越南五国。澜沧江-湄公 河是亚洲第六大河流, 是亚洲流经国家最多的国际 河流 ${ }^{[1]}$, 被称为 “东方的多瑙河”。

澜沧江-湄公河流域位于亚洲热带季风区, 受季 风影响，5 10 月为降水充沛的雨季，11 月 次年 4 月为干燥少雨的旱季。雨季流域区域暴雨频繁, 易 引发洪水泛滥; 而在旱季, 流域各地则易遭受干旱 [2]。冰雪融水是澜沧江-沣公河径流主要补给源, 近 年来随着全球气候变化, 青藏高原的冰雪消融响应 出现了加快趋势, 短期内它可能增加流域径流量, 使洪水灾害的风险加大; 但从长远来看, 这种趋势 可能会加剧高原地区水资源的短缺甚至枯竭。由于 人口的持续增长和社会经济的迅速发展, 流域各国 都在加大对河流水资源的开发利用, 生产、生活对 该河流依赖性更大, 这无疑会对澜沧江-湄公河流域 水环境造成更大负担, 既制约河流水质和流域社会 经济发展，同时对流域区水资源的无度使用、恶性 争夺和掠夺性开发等行为也会愈演愈烈, 进而引发 流域区的资源争端、地区稳定和环境生态危机。

目前, 气候变化背景下水资源危机风险的研究 尚不多, 且多以定性描述为主。为此本文基于风险 分析理论, 开展澜沧江-湄公河流域水资源危机的风 险评估研究, 初步建立了气候变化背景下澜沧江-湄 公河流域水资源危机风险的量化评估模型。

\section{2. 资料与方法}

\section{1. 研究对象}

本文从澜沧江-涺公河流域上游到下游依次选取 七个代表性的城市作为研究对象 (图1), 分别是: 我国境内的德钦、大理、景洪; 泰国的清莱; 老挝 的万象和巴色以及束埔寨的金边。

\section{2. 研究资料}

(1) 气象水文数据: 根据中国气象局气候中心和世 界气象组织的资料整理得到澜沧江-涺公河流域的降 水、气温、暴雨、干旱等气象要素数据; 根据云南 省水文信息网和世界江河数据库整理获得澜沧江-湄 公河的径流量、输沙量等水文要素。

(2) 社会人文数据：根据国际货币基金组织 (IMF)、斯德哥尔摩国际和平研究所 (SIPRI) 和世
界水资源发展报告等整理得到研究对象的水利发展 状况和社会经济等资源。

以上资料统计数据时间范围为 1961- 2008年。

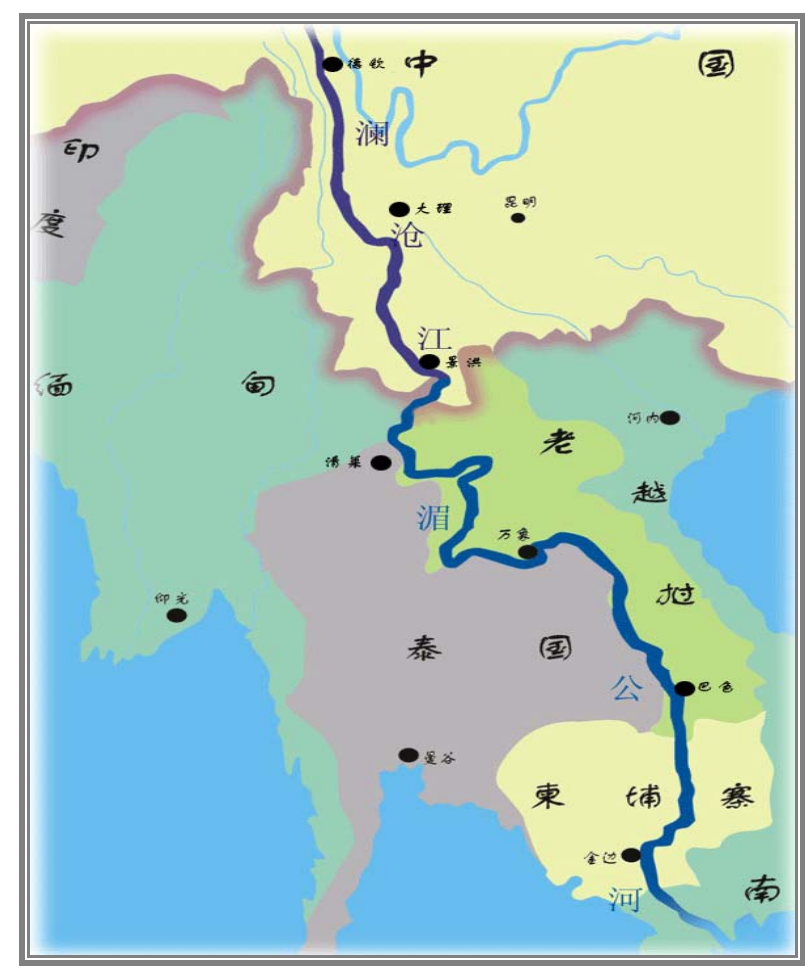

图 1 澜沧江-湄公河流域及城市示意图

\section{3. 研究方法}

根据灾害风险评价指数方法 ${ }^{[3-4]}$, 水资源危机风 险的形成是危险性 (H) 和脆弱性 (V) 共同作用的 结果, 数学表达式为:

水资源危机风险指数 $(R)=$ 危险性 $(H) \times$ 脆弱性 $(V)$ (1)

采用层次分析法 (AHP) 并结合Delphi法 ${ }^{[5-6]}$ 建 立指标体系和确定指标权重。为消除指标量纲差 异, 采用如下标准化公式对各指标标准化处理:

$$
X^{\prime}=\frac{X}{X_{\text {max }}-X_{\text {min }}}
$$

式中, $X^{\prime}$ 为某指标标准化后的值, $X$ 为该指标 的原始值, Xmin为研究范围内该指标的最小值, $X \max$ 为研究范围内该指标的最大值。

对于危险性和脆弱性各指标的合成采用加权综 合评价法 $(\mathrm{WCA})^{[7]}$, 计算公式为: 


$$
C_{j}=\sum_{i=1}^{n} W_{i} \cdot X_{i}
$$

式中， $C_{j}$ 表示评估项目 $j$ （危险性或脆弱性）的 计算值; $X_{i}$ 是对应于评估项目 $j$ 的指标 $i$ 的标准化值; $W_{i}$ 是指标 $i$ 权重; $n$ 是对应于评估项目 $j$ 的指标个数。

\section{3. 概念模型与评价指标}

\section{1. 概念模型}

风险是指遭受不利事件影响损失的可能程度, 是㭆险环境、致险因子和承险体相互作用的结果。 澜沧江-湄公河流域的水资源区域风险评估包括如下 三方面内容:

（1）危险性评估。通过对研究区域降水、温度和洪 涝干旱灾害强度、频率分布情况及变化趋势的统计 分析和预测结果, 给出气候致险因子的危险性大小 ${ }^{[8]}$; 针对地理人文环境进行成险机理分析, 从而确 定㝋险环境的危险性。在致险因子和孕险环境危险 性分析的基础之上, 综合得出研究对象的水资源危 机的危险性评估 ${ }^{[9]}$ 。

（2）脆弱性评估。即承险体在出现水资源短缺威胁 时可能的易损程度，主要包括四方面内容：1）承险 体暴露性评估, 即对处于争端风险中的人员、财 产、经济活动等承险体的数量 (或价值量) 及其分 布进行分析 ${ }^{[10]}$ ；2）承险体敏感性评估, 评估承险体 对水资源短缺和洪水干旱灾害响应能力；3）区域承 险能力评估, 即研究对象应对水资源短缺能力、防 治生态恶化和抵御洪水干旱灾害能力的评估, 它反 映的是人类社会应对风险的主观能动性。

（3）区域风险评估。是在危险性评估和脆弱性评估 的基础上, 对区域风险进行综合评估, 并以相对等 级的方式加以划分。

本文中气候变化背景下澜沧江-湄公河流域的水 资源危机风险是指由于冰雪融化和暴雨、干旱等气 候变化极端事件可能导致的水资源短缺、流域生态 恶化、水资源污染和旱涝灾害给澜沧江-湄公河流域 带来的损失风险。它是在一定的孕险环境中, 由致 险因子危险性和区域承险体脆弱性共同作用形成 的。基于上述分析, 建立了气候变化背景下澜沧江湄公河流域水资源危机风险概念模型（图2）。

\section{2. 指标体系}

根据上述水资源危机风险概念模型以及风险评 价指数法, 综合考虑指标选取的科学性、完备性、 相对独立性、系统性和现实可操作性原则, 建立了 如下水资源危机风险评价指标体系（图3）。
水资源危机风险为评估的目标层，由危险性指 标体系和承险体脆弱性指标体系两个子目标构成。 危险性指标体系包含致险因子和孕险环境两个评价 模块, 分别包含了降水平均值、干旱频率和植被覆 盖率等 8 个指标; 承险体脆弱性指标体系由物理暴 露性、敏感性和区域承险能力等三个评价模块构 成, 分别包含了人口密度、GDP 增长率、水资源利 用率等 12 个指标。

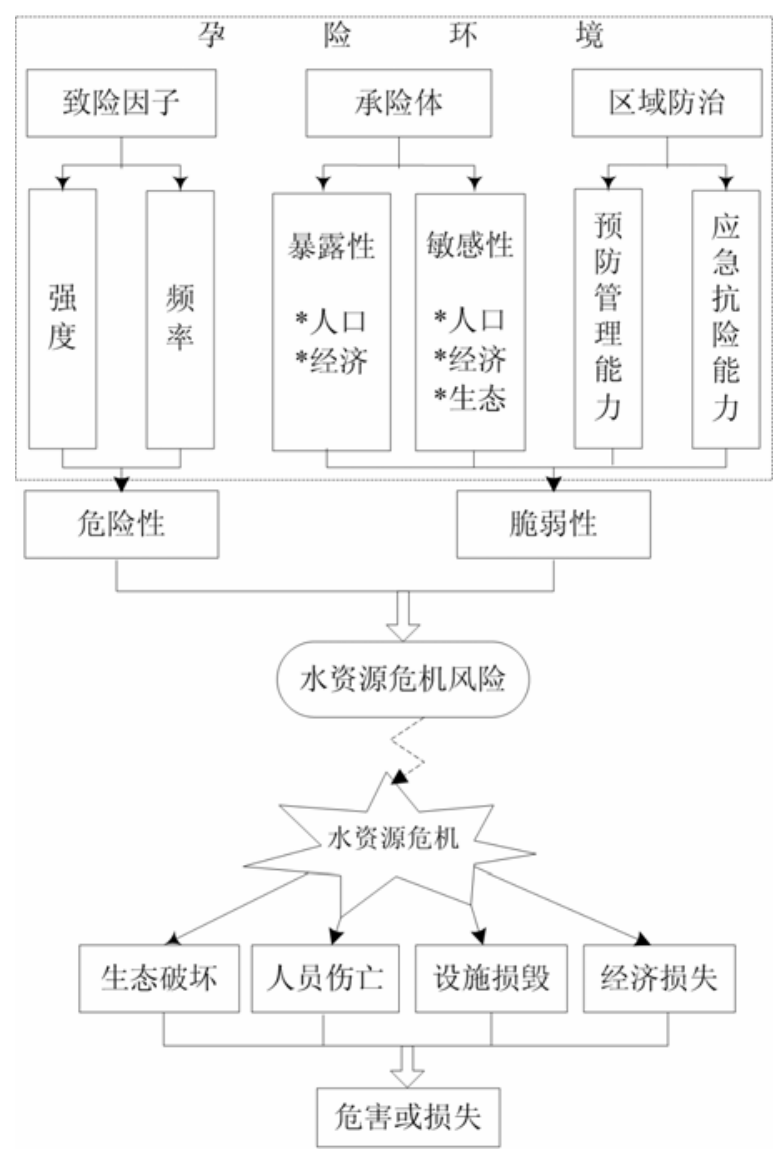

图 2 澜沧江-湄公河流域水资源危机风险概念模型

各指标的权重采用层次分析法（AHP）确定， 在构造判断矩阵时为了使计算结果更加合理可靠, 还可采用Delphi法广泛征求专家意见, 具体操作步 骤可参考相关文献 ${ }^{[4-5]}$ 。经一致性检验的权重计算结 果见图3中标注。

\section{3. 评估模型}

基于上述指标体系和公式（1）、（3），可建 立如下水资源危机风险评估模型： 


$$
\begin{aligned}
& R=H^{W_{H}} \bullet V^{W_{V}} \\
& H=X_{1}^{W_{1}} \bullet X_{2}^{W_{2}}
\end{aligned}
$$

$$
V=\sum_{i=3}^{6} W_{i} \bullet X_{i}
$$

其中, $X$ 为各指标标准化之后的量化值。

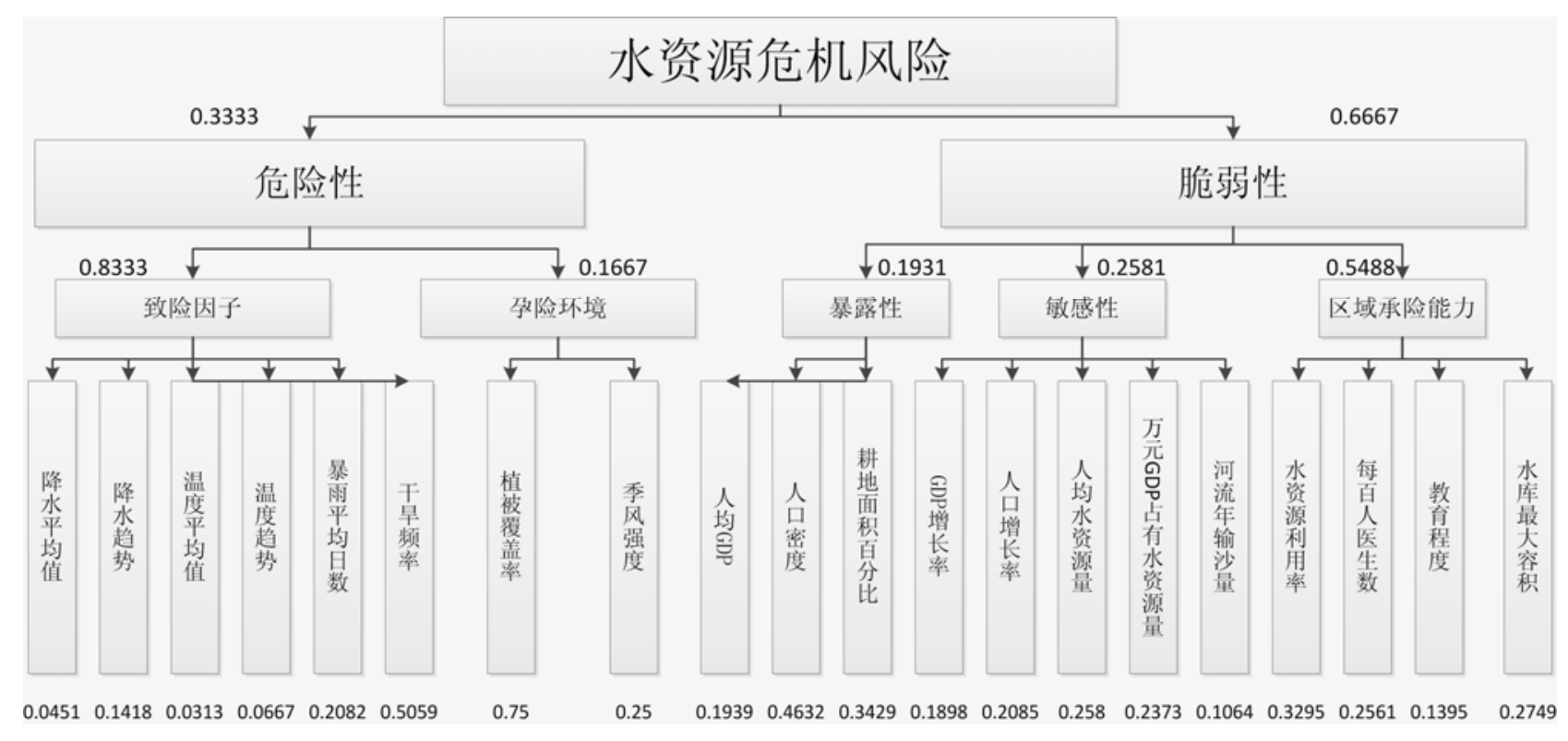

图 3 水资源危机风险指标体系（包括权重）

\section{4. 风险实验评估}

基于风险评估模型（6）～（8）和澜沧江-涺公 河流域七个城市的数据资料, 分别计算得到各评估 城市的水资源危机风险的危险性、脆弱性和风险度
指数（如表 1)。为了比较不同评估单元的危险性 程度, 用自然断裂法 ${ }^{[1]}$, 将危险度分为 5 级, 各等 级划分基准及各等级划分结果如表 2 。同理, 可得 到脆弱度和风险度的等级划分结果如表 3 和表 4 。

表 1 水资源危机风险指数评估结果

\begin{tabular}{cccccccc}
\hline 城 市 & 德钦 & 大理 & 景洪 & 清莱 & 万象 & 巴色 & 金边 \\
\hline 危险性指数 & 0.2285 & 0.7943 & 0.4879 & 0.157 & 0.6527 & 0.3819 & 0.7091 \\
脆弱性指数 & 0.1877 & 0.565 & 0.3479 & 0.2206 & 0.6937 & 0.4586 & 0.5077 \\
水资源风险度 & 0.1994 & 0.6416 & 0.3946 & 0.2013 & 0.68 & 0.433 & 0.5748 \\
\hline
\end{tabular}

表 2 水资源危机风险危险度等级划分

\begin{tabular}{cccccc}
\hline 等 级 & 极高 & 较高 & 中等 & 较低 & 极低 \\
\hline 危险性指数 & $\geqslant 0.7$ & $0.55 \sim 0.69$ & $0.35 \sim 0.549$ & $0.0 .2 \sim 0.349$ & $\leq 0.19$ \\
城 市 & 大理、金边 & 万象 & 景洪、巴色 & 德钦 & 清莱 \\
\hline
\end{tabular}

表 3 水资源危机风险脆弱度等级划分

\begin{tabular}{cccccc}
\hline 等 级 & 极高 & 较高 & 中等 & 较低 & 极低 \\
\hline 脆弱性指数 & $\geqslant 0.6$ & $0.5 \sim 0.59$ & $0.4 \sim 0.49$ & $0.25 \sim 0.39$ & $\leq 0.249$ \\
城 市 & 万象 & 大理、金边 & 巴色 & 景洪 & 清莱、德钦 \\
\hline
\end{tabular}


表 4 水资源危机风险度等级划分

\begin{tabular}{cccccc}
\hline 等 级 & 风险极高 & 风险较高 & 风险中等 & 风险较低 & 风险极低 \\
\hline 风险度 & $\geqslant 0.6$ & $0.5 \sim 0.59$ & $0.4 \sim 0.49$ & $0.25 \sim 0.399$ & $\leq 0.249$ \\
城 市 & 万象、大理 & 金边 & 巴色 & 景洪 & 清莱、德钦 \\
\hline
\end{tabular}

万象和金边均为世界上重要的粮食生产区，对水 资源的需求较大, 万象和金边作为老挝和束埔寨的首 都, 是国际性旅游城市, 人口密度大、水资源消耗 多, 导致其危险性、脆弱性偏高 ${ }^{[12]}$ 。相比以上两个城 市, 虽然大理的灌溉面积要小许多, 但其作为著名的 旅游城市, 外来人口多、水资源消耗大。近年来, 大 理地区频繁遭遇干旱和洪涝等极端天气事件, 导致水 资源危机的危险性和脆弱性均较高。综上因素综合评 价：大理、万象为水资源高风险城市，金边为水资源 较高风险城市, 巴色为中等风险城市。泰国清莱和我 国景洪虽然较易发生洪灾, 但人口相对较少、经济欠 发达、且森林覆盖率较高, 脆弱性较小, 进而水资源 危机风险偏小。我国德钦为山区, 灌溉面积少、植被 覆盖率高, 干旱的强度和频率较小, 故其水资源危机 风险最小。

气候变化对水资源的影响因子众多、影响机理复 杂; 水资源对于社会经济发展的作用过程既包含自然 环境因素、也包含社会与人文因素。气候变化风险首 先是通过自然环境响应的物理机理影响流域降水和径 流; 水资源的变异再通过社会机理等过程对流域边境 各国的生产生活、政治经济、军事外交等产生影响， 进而诱发流域地区风险和危机事件。本文由于资料有 限, 评价指标比较简单, 仅对流域水资源危机风险作 了初步探讨。下一步工作中，我们将进一步考虑自然 和社会因素，充实、完善和扩展指标体系与相应的评 估模型，以使评价体系和评估模型更加科学、合理。

\section{致谢: 气象灾害教育部重点实验室开放课题（KLME1112）}

\section{参考文献}

[1] 李丽娟, 李海滨, 王娟. 澜沧江水文与水环境特征及其时 空分异. 地理科学, 2002, 22(1): 49-56.

Li lijuan, Li haibin, Wang juan. Analysis on hydrological and water quality character and theirspatial and temporal distribution in Lancangjiang River. Scientia Geographica Sinica, 2002, 22(1): 49-56.

[2] HE Daming,ZHAO Wunjuan,FENG Yan. Research progress of international rivers in China. Journal of Geographical Sciences,2004,21:21-28.

[3] Davidson R A, Lamber K B. Comparing the hurricane disaster risk of U. S. coastal counties. Natural Hazards Review, 2001, 8:132-142.
[4] 杜栋, 庞庆华, 吴炎. 现代综合评价方法与案例精选. 北 京:清华大学出版社, 2008.Du Dong, Pang Qinghua, Wu Yan. Modern comprehensive assessment method and case selection. Beijing, Tsinghua University Press, 2008.

[5] 何逢标. 综合评价方法 MATLAB 实现. 北京: 中国社会 科学出版社, 2010 .

He Fengbiao. Implementation of comprehensive evaluation method by using MATLAB language. Bejing: Chinese Social Science Press, 2010.

[6] 文世勇, 赵冬至, 陈艳拢. 基于 AHP 法的赤潮灾害风险 评估指标权重研究. 灾害学, 2007, 22(2): 9-14.

Wen Shiyong, Zhao Dongzhi, Chen yanlong. Research on index weighting of risk assessment of harmful algal Bloom hazard based on AHP. Journal of Catastrophology. 2007, 22(2): 9-14.

[7] 张继权, 魏民. 加权综合评分法在区域玉米生产水平综 合评价与等级分区中的应用. 经济地理, 1994, 14(5): 1921.

Zhang Jiquan, Wei Min. The implementation of weighted comprehensive evaluation method in corn production level and grades. Economic Geography,1 994, 14(5): 19-21.

[8] 黄崇福. 综合风险评价的一个基本模式. 应用基础与工 程科学学报, 2008, 16(3): 371-381.

Huang Chongfu. A basic model for assessing integrated risk. Journal of basic science and engineering, 2008, 16(3): 371-381.

[9] 黎金金, 张韧. 南海-印度洋海域海洋环境风险评估与区划. 气象水文装备, 2010, 21(6): 14-20.

Li Xin, Zhang Ren. Risk assessment and regionalization of ocean environment in the South China Sea and Indian Ocean. Meteorological and Hydrological Equipments, 2010, 21(6): 14-20.

[10]葛全胜, 邹铭, 郑景云等. 中国自然灾害风险综合评价初 步研究. 北京: 科学出版社, 2008.

Ge Quansheng, Zou Ming, Zheng Jingyun, et al. Integrated assessment of natural disaster risks in China. Beijing: Science Press, 2008.

[11]黎金金. 南海-印度洋海域海洋环境风险分析体系与评估技 术研究. 南京: 解放军理工大学, 2010.

$\mathrm{Li}$ Xin. The research of risk assessment and regionalization of ocean environment in the South China Sea and Indian Ocean. Nanjing: PLA University of Science and Technology, 2010.

[12]何大明, 王玉朝, 何希吾等. 西南国际河流跨境水资源的 合理利用和可再生性维持研究.中国自然资源学会 2004 年学术年会论文集, 2004, 410-417.

He Daming, Wang Yuchao, He Xiwu, et al. Study for the rational use and sustainability of international rivers in Southwestern China. Paper compilation of China Society of Natural Resources in 2004, 2004, 410-417. 